\title{
Influence of small-group experiential learning of integrated traditional Chinese and Western medicine on the oral health knowledge, beliefs, and behaviors of elderly patients with diabetes
}

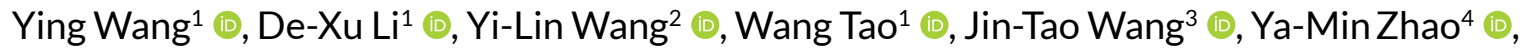 \\ Ling-Ling $\mathrm{Li}^{5}$ (1), Yan-Ling Li ${ }^{5 *}$ (1)
}

\begin{abstract}
SUMMARY
OBJECTIVE: This study aimed at the oral health problems of elderly patients with diabetes. A training course of integrated traditional Chinese and Western medicine was constructed, helping patients improve their oral health quality of life.

METHODS: A randomized controlled prospective experimental study was conducted. A total of 190 elderly patients were divided randomly into an observation group and a control group with 95 cases in each. The control group received regular health education, while the observation group was based on the control group to implement the integrated experiential learning of traditional Chinese and Western medicine in small groups. The oral health knowledge, attitude, behavior, and blood glucose control status along with the oral health quality of life of the two groups were compared before the intervention and at 3-month postintervention.

RESULTS: Three months after the intervention, the fasting blood glucose control and the 2-h postprandial blood glucose/glycosylated hemoglobin levels in the observation group were significantly better than in the control group, and the difference was statistically significant ( $p<0.05$ ). The oral health quality of life in the observation group was significantly better than in the control group, and the difference was statistically significant ( $p<0.05)$. CONCLUSION: The small-group experiential learning model of integrated Chinese and Western medicine can promote the transformation of knowledgebeliefs-behaviors in elderly patients with diabetes, which is conducive to controlling blood sugar levels and improving the quality of oral health. KEYWORDS: Diabetes mellitus. Integrated traditional Chinese and Western medicine. Small-group experiential learning. Oral health knowledge. Oral health attitude. Oral health behavior. Blood sugar level. Glycosylated hemoglobin. Oral health quality of life.
\end{abstract}

\section{INTRODUCTION}

Diabetes is a common endocrine and metabolic disease. It causes a series of complications, such as glaucoma, diabetic neuropathy, cataracts, oral or skin infections, and periodontal disease ${ }^{1,2}$, threatening the health and life of the patient and placing a burden (of which oral disease is one) on the patient's family and on wider society. Oral problems are chronic inflammatory diseases, of which periodontal disease is one of the most prevalent chronic infections among adults, affecting more than $22 \%$ of diabetics ${ }^{3}$. Traditional Chinese medicine (TCM) believes that there are many fire syndromes in patients with oral diseases; these can be divided into actual and virtual fire ${ }^{4}$. Elderly patients should be treated according to their different clinical symptoms and the characteristics of elderly people to reduce oral disease caused by diabetes. Western medicine believes that if the patient's own blood sugar level is not well controlled, it can result in various infections in the oral cavity very easily, such as periodontal disease and oral mucosal lesions. Studies have clarified the two-way relationship between diabetes and oral health. Several studies have shown that periodontal treatment can improve glycemic control, most likely by improving insulin sensitivity 5 . To improve the oral problems of elderly patients with diabetes, in addition to controlling blood sugar, it is necessary to reinforce health education on oral problems. The smallgroup education model is a patient-centered model that fully encompasses the characteristics of the autonomy, interaction, and mutual assistance of group health education and provides the advantages of faster and more interesting learning than is

\footnotetext{
${ }^{1}$ Affiliated Hospital of Hebei University, Department of Integrated Traditional Chinese and Western Medicine - Baoding, China.

${ }^{2}$ Shandong University, School of Basic Medicine - Jinan, China.

${ }^{3}$ Affiliated Hospital of Hebei University, Department of Stomatology - Baoding, China.

${ }^{4}$ Affiliated Hospital of Hebei University, Department of Endocrinology - Baoding, China.

${ }^{5}$ Affiliated Hospital of Hebei University, Department of Tuberculosis - Baoding, China.

*Corresponding author: yanlinglidr@163.com

Conflicts of interest: the authors declare there is no conflicts of interest. Funding: This work was supported by the Research project of traditional Chinese medicine in bureau of Hebei provincial traditional Chinese medicine administration in 2019 (approval number: 2019178).

Received on November 01, 2021. Accepted on December 05, 2021.
} 
possible individually ${ }^{6,7}$. Experiential learning allows learners to understand and use certain skills more flexibly through their own experiences and observations ${ }^{8}$. Both forms strengthen the communication and cooperation between educators and patients.

To explore the effects of oral health education on the control of blood glucose, this study used small-group experiential learning to educate elderly patients with diabetes and oral disease by means of integrated Chinese and Western medicine self-care training and combined the concept of TCM syndrome differentiation with holistic nursing. The training improves patients' awareness of diabetic oral health, strengthens positive attitudes, changes negative behaviors, and improves the oral health of elderly patients with diabetes.

\section{METHODS}

\section{Research objects}

Using a convenient sampling method, the study selected 190 elderly patients with diabetes and oral disease who were treated in the Department of Endocrinology, Stomatology, and Integrated Traditional Chinese and Western Medicine in our hospital from February 2020 to January 2021. Using the random number table method, the study subjects were allocated to an observation group or a control group, each with 95 cases. The admission criteria were as follows: (1) age $\geq 60$ years, (2) compliance with diabetes with a diagnosis time of $>1$ year, (3) hospital stay $>3$ days, and (4) informed consent. The exclusion criteria were as follows: (1) patients with oral diseases caused by trauma and other reasons, (2) patients with acute complications, and (3) patients with severe liver/kidney damage or cardiovascular/cerebrovascular diseases. There was no statistically significant difference in the general data between the two groups of patients. There were 95 patients in the intervention group, $4(4.2 \%)$ of which were lost after 3 months, and there were 95 patients in the control group, 3 (3.2\%) of which were lost after 3 months. Comparing the loss rate of the two groups, the difference was not statistically significant $\left(\chi^{2}=0.356, p>0.05\right)$.

\section{Research methods}

\section{The review of the training course}

In the control group, the traditional methods of delivering health education were performed. In the observation group, the elderly patients with diabetic oral diseases were trained in integrated Chinese and Western medicine self-care on the basis of Western medicine health education, and the characteristics of TCM were highlighted, including frequent gargling and checking of cheeks after every meal. In dietary conditioning, according to the logical relationship between food and medicine and the same treatment of food and medicine, patients with diabetes should consume light, cool, nutritious, high-quality protein and multifiber foods and avoid fat, sweet flavors, mellow wine, barbecues, and spicy stimulants. Attention should be paid to the temperature of food. It is advisable to consume food that is "hot without burning lips and cold without shaking teeth" . In terms of daily lifestyle and health, daily lifestyle methods were introduced that adapt to the four seasons, combine the dynamic and static, and consider the moderate activity method of work and rest. Emotional adjustment recording involved explaining to patients the relationship between emotion and health, guiding self-relaxation, and suppressing seven different emotions that lead to disease ${ }^{10-12}$.

\section{Implementation and evaluation}

The data were collected based on the oral health knowledge, attitude, behavior, and the oral health quality of life of the two groups of patients for 3 months after intervention. The fasting blood glucose levels and the 2-h postprandial blood glucose and glycosylated hemoglobin data of the two groups of patients were collected.

\section{Research tools}

The oral Health Knowledge, Attitude, and Behavior Questionnaire for Elderly Diabetic Patients ${ }^{13}$ was used in our study. The higher the score, the better the patient's oral behavior. In addition, the higher the score, the worse the patient's oral health and oral quality of life for the Chinese version of the Oral Health Quality of Life Evaluation Index for the Elderly.

\section{Statistical processing}

The data were analyzed using SPSS 22.0 statistical software. Statistical methods used included descriptive statistics, t-tests, analysis of variance, and $\chi^{2}$ tests. Enumeration data were expressed in the form of frequency, and measurement data were expressed using mean and standard deviation. $\mathrm{p}<0.05$ was a statistically significant score.

\section{RESULTS}

\section{Comparison of blood glucose control between the two groups of patients before and after intervention}

The results showed no significant difference in the control of blood glucose (fasting blood glucose and 2-h postprandial blood 
glucose/glycosylated hemoglobin levels) between the two groups before intervention (all were $\mathrm{p}>0.05$ ). After the application of the intervention, the intervention group's blood glucose (fasting blood glucose and postprandial blood glucose) and 2-h blood glucose/glycosylated hemoglobin levels were better than the control group, and the differences were statistically significant (all were $\mathrm{p}<0.05$ ) (see Table 1 ).

\section{Comparison of oral health knowledge,} attitudes, and behaviors between the two groups of patients before and after intervention

The results revealed that the oral health knowledge, attitude, and behavior scores of the two groups of patients before intervention were not statistically different (all were $\mathrm{p}>0.05$ ). After intervention, the oral health knowledge, attitude, and behavior scores of the intervention group were higher than those of the control group. The differences were statistically significant (all were $\mathrm{p}<0.05$ ) (see Table 2).

\section{Comparison of oral health quality-of-life scores between the two} groups of patients before and after intervention

The results revealed that after intervention, the oral health quality-of-life scores of patients in the intervention group were higher than those in the control group, and the difference between the two groups was statistically significant (all were $\mathrm{p}<0.05$ ) (see Table 3 ).

Table 1. Comparison of blood glucose control between the two groups before and after intervention.

\begin{tabular}{l|c|c|c|c|c|c|c}
\multirow{2}{*}{ Group } & \multirow{2}{*}{ Cases } & \multicolumn{2}{|c|}{ Fasting blood glucose } & 2-h postprandial blood glucose & \multicolumn{2}{c}{ Glycated hemoglobin } \\
\cline { 2 - 7 } & $\begin{array}{c}\text { Before } \\
\text { intervention }\end{array}$ & $\begin{array}{c}\text { After } \\
\text { intervention }\end{array}$ & $\begin{array}{c}\text { Before } \\
\text { intervention }\end{array}$ & $\begin{array}{c}\text { After } \\
\text { intervention }\end{array}$ & $\begin{array}{c}\text { Before } \\
\text { intervention }\end{array}$ & $\begin{array}{c}\text { After } \\
\text { intervention }\end{array}$ \\
\hline Control group & 92 & $8.28 \pm 1.02$ & $7.49 \pm 0.85$ & $10.82 \pm 1.86$ & $10.59 \pm 1.81$ & $8.02 \pm 0.81$ & $7.25 \pm 0.86$ \\
\hline $\begin{array}{l}\text { Intervention } \\
\text { group }\end{array}$ & 91 & $8.33 \pm 1.17$ & $6.91 \pm 1.78$ & $11.29 \pm 2.04$ & $9.55 \pm 1.22$ & $8.36 \pm 1.66$ & $6.58 \pm 1.26$ \\
\hline$T$ & & -0.306 & 2.830 & -1.625 & 4.555 & -1.776 & 4.171 \\
\hline$p$ & & $>0.05$ & $<0.05$ & $>0.05$ & $<0.05$ & $>0.05$ & $<0.05$ \\
\hline
\end{tabular}

Table 2. Comparison of oral health knowledge, attitude, and behavior scores between the two groups of patients before and after intervention.

\begin{tabular}{l|c|c|c|c|c|c|c}
\multirow{2}{*}{ Group } & \multirow{2}{*}{ Cases } & \multicolumn{2}{|c|}{ Knowledge } & \multicolumn{2}{c}{ Attitude } & \multicolumn{2}{c}{ Behavior } \\
\cline { 3 - 7 } & $\begin{array}{c}\text { Before } \\
\text { intervention }\end{array}$ & $\begin{array}{c}\text { After } \\
\text { intervention }\end{array}$ & $\begin{array}{c}\text { Before } \\
\text { intervention }\end{array}$ & $\begin{array}{c}\text { After } \\
\text { intervention }\end{array}$ & $\begin{array}{c}\text { Before } \\
\text { intervention }\end{array}$ & $\begin{array}{c}\text { After } \\
\text { intervention }\end{array}$ \\
\hline Control group & 92 & $3.40 \pm 3.58$ & $3.78 \pm 3.34$ & $20.80 \pm 9.71$ & $21.62 \pm 8.50$ & $40(43.48 \%)$ & $49(53.26 \%)$ \\
\hline $\begin{array}{l}\text { Intervention } \\
\text { group }\end{array}$ & 91 & $2.92 \pm 3.65$ & $5.86 \pm 2.75$ & $20.30 \pm 9.07$ & $24.20 \pm 5.21$ & $36(39.56 \%)$ & $66(72.53 \%)$ \\
\hline$t / \square 2$ & & $0.897^{a}$ & $-4.586^{\mathrm{a}}$ & $0.357^{\mathrm{a}}$ & $-2.470^{\mathrm{a}}$ & $0.289^{\mathrm{b}}$ & $7.273^{\mathrm{b}}$ \\
\hline $\mathrm{p}$ & & $>0.05$ & $<0.05$ & $>0.05$ & $<0.05$ & $>0.05$ & $<0.05$ \\
\hline
\end{tabular}

Note: ${ }^{\text {TThe }}$-value of two independent samples t-test; ${ }^{\circ}$ The chi-square value.

Table 3. Comparison of oral health quality-of-life scores between the two groups before and after intervention.

\begin{tabular}{l|c|c|c}
\hline Group & Cases & Before intervention & After intervention \\
\hline Control group & 92 & $21.14 \pm 12.08$ & $19.41 \pm 13.27$ \\
\hline Intervention group & 91 & $21.51 \pm 11.64$ & $15.79 \pm 10.12$ \\
\hline$T$ & & -0.208 & 2.074 \\
\hline$p$ & & $>0.05$ & $<0.05$ \\
\hline
\end{tabular}




\section{DISCUSSION}

\section{Small-group experiential \\ learning with integrated traditional \\ Chinese and Western medicine can improve patients' blood sugar control}

The control group adopted the traditional health education model, and although the blood glucose control of the patients improved, it did not reach the ideal level. The intervention group implemented the small-group experiential learning program of integrated traditional Chinese and Western medicine. Both the fasting blood glucose and after-meal levels (2-h blood sugar and glycosylated hemoglobin) in this group dropped significantly. The results of our study were consistent with the results of previous studies. Health guidance and health education by dentists, physicians, and diabetes educators to enhance quality of life have been reported to be remarkably effective ${ }^{14}$. Goodson et al. ${ }^{15}$ assessed salivary glucose concentrations and other oral factors, such as dental caries and gingivitis, in patients with diabetes. In this study, high salivary glucose was associated with a reduction in the overall number of bacteria in saliva and a change in bacterial frequency in 8,173 patients. In addition, Cortelli et al. ${ }^{16}$ estimated the impact of gingivitis treatment on oral health-related quality of life (OHRQoL). This treatment improved the quality of life and highlighted the correlation between periodontal care and the individual's daily life. The reason is that small-group experiential learning of integrated Chinese and Western medicine rejects unilateral cramming-style teaching and focuses on the acceptance and emotional responses of elderly patients, allowing them to feel fully respected, understood, and accepted. Moreover, experiential learning emphasizes that in the process of mastering knowledge and skills, not only can people "know and act," they can also gain experience improvement from deep reflection ${ }^{17}$. All these factors enable patients to recognize diabetes correctly and help reduce blood sugar levels.

\section{Small-group experiential learning with integrated traditional Chinese and Western medicine can improve patients' oral health knowledge, beliefs, and actions}

Elderly patients with diabetes have poor oral health knowledge, beliefs, and behaviors, and they lack an understanding of the relationship between diabetes and periodontitis ${ }^{18}$. Li Yanling's research ${ }^{19}$ shows that most people do not understand the close relationship between the two. Only after experiencing oral health problems, patients gain a certain understanding of this relationship. More than half of the patients have never received information about diabetes management and oral health from their healthcare providers, and preventive oral healthcare is not included in diabetes management programs. Research ${ }^{20}$ shows that by communicating, preaching, and learning from each other's experiences, patients can help others to strengthen their beliefs, improve poor lifestyle habits, and develop good oral behaviors. An overseas survey revealed that more than half of the patients who visited a clinic for a year considered it unnecessary to undergo an outpatient oral examination ${ }^{21}$, indicating that a firm belief in oral health had not been formed at that point. Surveys by Li Yanling and others show that more than half of elderly patients with diabetes lack oral health knowledge. The reason is that diabetes oral health education is rarely delivered in China; some of them are only at the level of traditional knowledge, and the content is not comprehensive. Consistent with the conclusions of other studies, the oral health education of elderly patients with diabetes adopts only a single form, and there is an urgent need to include multiple methods and channels of oral health education for elderly patients with diabetes to reduce the incidence of oral diseases.

\section{Small-group experiential learning with integrated traditional Chinese and Western medicine can improve patients' oral health and quality of life}

In recent years, with the transformation in medical models, people's concepts of health have developed from being historically disease free to have a good standard of all aspects of their own physical, psychological, and social activities. Therefore, introducing the "quality of life" evaluation index into the field of stomatology to evaluate the impact of oral diseases on patients' physical, psychological, and social functions is more suited to modern health perspectives ${ }^{22}$. As the course of the disease progresses in patients with diabetes, their oral quality of life gradually deteriorates ${ }^{23}$. Studies have shown that the oral health quality of life of elderly patients with diabetes in China is at a low-tomedium level. The impact of oral health problems, including periodontal disease, on the quality of life of elderly patients with diabetes mainly includes oral physiological functions, oral-related behavioral influences, cognitive problems, and psychological function $s^{24}$. Health education can improve patients' awareness of diabetes and their knowledge of related oral health issues, enhance their oral healthcare capabilities, change their poor oral health behaviors, and improve their oral health quality of life ${ }^{25}$.

Our study considered both the characteristics of the elderly and the educational content and implemented targeted smallgroup experiential learning of integrated Chinese and Western medicine in a scientific and effective new health education 
model to assist elderly patients with diabetes in controlling their blood sugar levels. Stomatology, endocrinology, geriatrics, and other related departments must strengthen their collaboration to help elderly patients with diabetes develop good oral health knowledge, beliefs, and behaviors to achieve a decent oral health quality of life and to promote recovery ${ }^{26}$.

\section{CONCLUSION}

This study integrates Chinese group experiential learning mode and promotes knowledge, belief and behavior changes in elderly diabetic patients, which helps to control blood sugar level and improve oral health quality. To achieve decent oral health, quality of life and promote rehabilitation.

\section{REFERENCES}

1. Martinez-Millana A, Argente-Pla M, Valdivieso Martinez B, Traver Salcedo V, Merino-Torres JF. Driving type 2 diabetes risk scores into clinical practice: performance analysis in hospital settings. J Clin Med. 2019;17;8(1):107.https://doi.org/10.3390/jcm8010107

2. Ebbeling CB, Young IS, Lichtenstein AH, Ludwig DS, McKinley M. Perez-Escamilla R, et al. Dietary fat: friend or foe? Clin Chem. 2018;64(1):34-41.https://doi.org/10.1373/clinchem.2017.274084

3. Pérez-Losada FL, Estrugo-DevesaA, Castellanos-Cosano L, SeguraEgea JJ, López-López J, Velasco-Ortega E. Apical periodontitis and diabetes mellitus type 2: a systematic review and meta-analysis. J Clin Med. 2020;9(2):540. https://doi.org/10.3390/jcm9020540

4. Shen H, Zhu L, Gu J. Chinese medicine treatment of oral ulcers. J Nanjing Univ Tradit Chin Med. 2015;31(03):218-9+230.

5. Cervino G, TerranovaA, Briguglio F, Stefano R, Famà F, D'Amico C, et al. Diabetes: oral health related quality of life and oral alterations. BioMed Res Int.2019;2019:5907195.https://doi.org/10.1155/2019/5907195

6. Edmunds S, Brown G. Effective small group learning: AMEE Guide No. 48. Med Teach. 2010;32(9):715-26. https://doi.org/10.3109 /0142159X.2010.505454

7. Li BS, Hou QM. Effect of small group scenario simulation training on self-care ability and self-efficacy among tumor patients with peripherally inserted central catheter. Nurs J Chin People's Liberation Army. 2016;33(13):28-31.

8. Liu YQ, Yan J. An overview of experience and its application in nursing. J Nurs. 2014;(16):14-6.

9. Wei YY, Li YL, Tian HY, Gao YP, Shi LN. Experience in nursing care of oral health of elderly type 2 diabetic patients with integrated traditional Chinese and western medicine. Hebei J Tradit Chin Med. 2014;36(10):1571-2.

10. Zhu CY, GuoSS, Liang XC. Exploration of Chinese medicine indices and prescriptions for diabetes mellitus. Shanghai J Tradit Chin Med. 1982(06):5-6.

11. Zhao XJ, Zhang HM. Observation on the effect of combined Chinese and Western medical care in elderly diabetic patients. World Latest Med Inf. 2018;18(96):252.

12. Wu LT, Deng WY. Application of integrated traditional Chinese and Western medicine in elderly patients with hypertension and type 2 diabetes mellitus. World Latest Med Inf. 2018;18(55):213+215.

13. Wu LK. The relationship between blood glucose, oral hygiene knowledge, attitudes and behaviors of patients with type 2 diabetes

\section{ETHICS APPROVAL}

This study was conducted in accordance with the Declaration of Helsinki. This study was conducted with approval from the Ethics Committee of Affiliated Hospital of Hebei University. Written informed consent was obtained from all participants.

\section{AUTHORS' CONTRIBUTIONS}

YW made substantial contributions to conception and design. DXL, YLW contributed for acquisition of data, analysis, and interpretation of data. WT, JTW were involved in drafting this manuscript and revising it critically for important intellectual content. YMZ, LLL, YLL gave final approval of the version to be published. YW, DXI authors contributed equally.

and periodontal disease. Master's thesis of the Institute of Dental Hygiene, Kaohsiung Medical University. 2004:85-8.

14. Cinar AB, Oktay I, Schou L. "Smile healthy to your diabetes": health coaching-based intervention for oral health and diabetes management. Clin Oral Investig. 2014;18(7): 1793-801. https:// doi.org/10.1007/s00784-013-1165-2

15. Goodson JM, Hartman ML, Shi P, Hasturk H, Yaskell T, Vargas J, et al. The salivary microbiome is altered in the presence of a high salivary glucose concentration. PLoS One. 2017;12(3):e0170437. https://doi.org/10.1371/journal.pone.0170437

16. Cortelli SC, Costa FO, Gargioni-Filho A, Aquino DR, Cota LOM, Scherma AP, et al. Impact of gingivitis treatment for diabetic patients on quality of life related to periodontal objective parameters: a randomized controlled clinical trial. Arch Oral Biol. 2018;86:80-6. https://doi.org/10.1016/j.archoralbio.2017.11.010

17. Zhang L, Liu J, Yan CL, Zhao ZH, Tang JJ, MaXC. Application research on experiential learning in insulin injection skills education of type 2 diabetic patients. Chin Nurs Res. 2016;30:1362-5.

18. Xin WN. Validation and application research of scale on oral health life quality. Master's thesis of Sun Yat-sen University. 2006.

19. LiYL,TianYQ,JiPX,DongX,LiQ,TianHY.Oralhealthcareneeds ofelderly patients with type 2 diabetes. Chin J Gerontol. 2016;36(19):4913-4.

20. Zhang H,PanZX.Application of KAPhealtheducation modefor diabetes dental implanted patients. Chin J Oral Implantol. 2017;22(4):182-4.

21. Sebai I, Temessek A, Chelly A, Harrabi T, Mami FB. Assessment of oral health status among uncontrolled diabetic mellitus patients in Tunisia. Tunis Med. 2019;97(2):307-13. PMID: 31539088

22. Li JY, Lu LX, Li J, Deng M, Huang LW, Lu DW, et al. The impact of diversified healtheducation on the oral health quality of life of elderly diabetic patients inwestern Guangxi. J Nurs Train.2016;31(16):1513-5.

23. Duan XJ, Jin CD, Yan JN. The level and influence factors of oral health-related quality of life in elderly patients with diabetes. Chin J Nurs. 2015;50(3):313-7.

24. Yuan CX, Chen X, Yan J. Research progress of oral health quality and influencing factors in elderly patients with diabetes. J Nurs Sci. 2018;33(10):20-2.

25. Jia JL, Jia N, Cheng L. Analysis and investigation on oral health quality of life and influencing factors in elderly patients with type 2 diabetes mellitus. J Qilu Nurs 2017;23(1):20-2.

26. Xue W, Cheng YX, Li LJ, Tang CH. Comprehensive management of oral health care for patients with type 2diabetes and senile periodontitis. Chin J Gerontol. 2020;40(22):4910-12. 